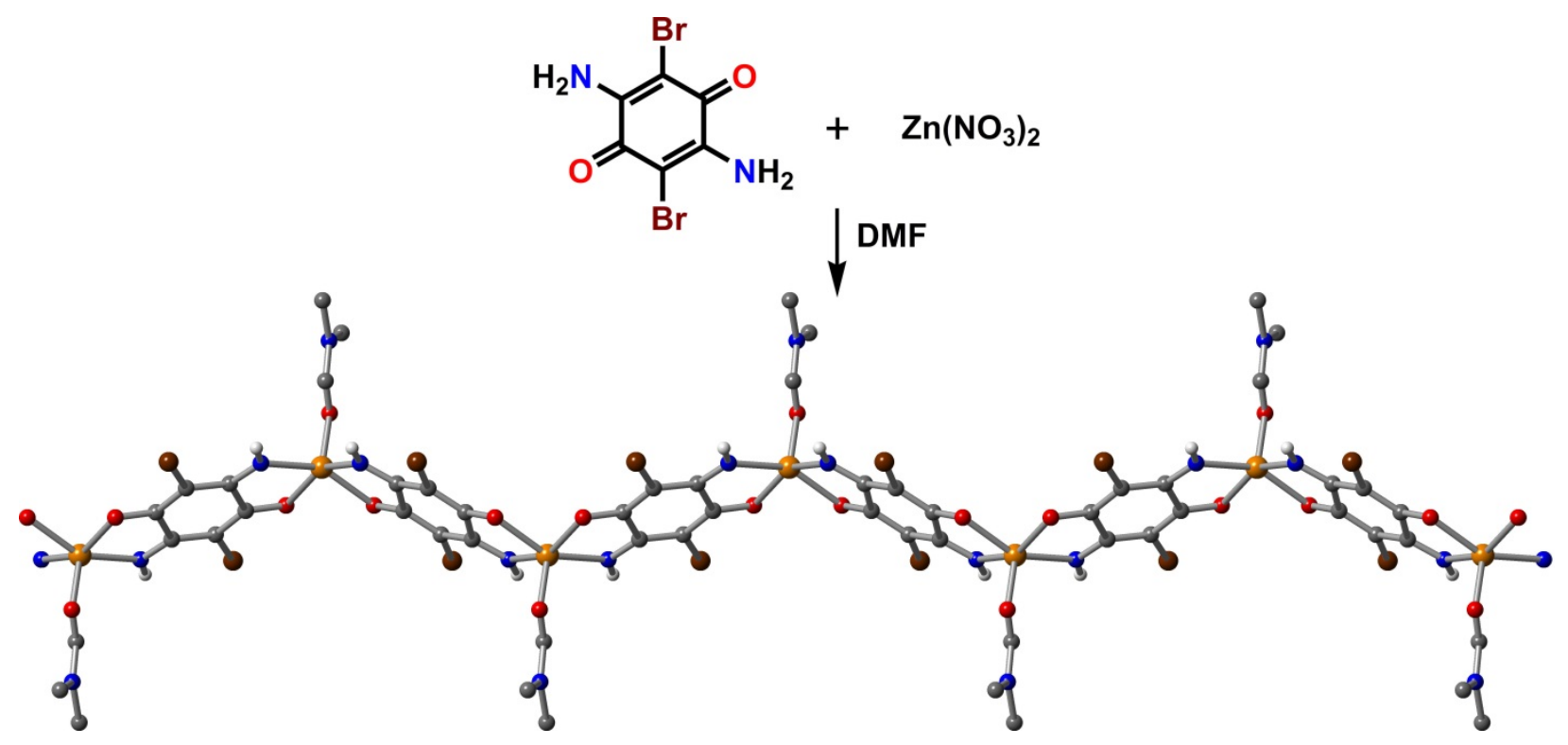

ABSTRACT FOR WEB PUBLICATION. The incorporation of amino-substituted benzoquinoid bridging ligands into extended solids may provide a route to access light-weight metal-organic solids with high-temperature magnetic behavior and electronic conductivity. Reaction of $\mathrm{Zn}\left(\mathrm{NO}_{3}\right)_{2} \cdot 6 \mathrm{H}_{2} \mathrm{O}$ with 2,5-diamino-3,6-dibromo-1,4-benzoquinone $\left({ }^{\mathrm{Br}} \mathrm{LH}_{2}\right)$ in DMF at $130{ }^{\circ} \mathrm{C}$ gave black block-shaped single crystals of the compound $\mathrm{Zn}\left({ }^{\mathrm{Br}} \mathrm{L}\right)(\mathrm{DMF})$, which features a structure comprised of one-dimensional chains made up of alternating $\mathrm{Zn}{ }^{\mathrm{II}}$ ions and ${ }^{\mathrm{Br}} \mathrm{L}^{2-}$ bridging ligands. The preservation of $\mathrm{NH}$ groups on ${ }^{\mathrm{Br}} \mathrm{L}^{2-}$ was confirmed by X-ray crystallography, a suite of spectroscopic measurements, and elemental analysis. To our knowledge, this chain compound represents the first structurally-characterized solid that contains amino-substituted benzoquinoid bridging ligands. Finally, an ambient temperature electronic conductivity value of $\sigma=1.076(5) \times 10^{-12} \mathrm{~S} \cdot \mathrm{cm}^{-1}$ was measured for the chain compound. 


\title{
A Structurally-Characterized Zinc 2,5-Diiminobenzoquinoid Chain Compound
}

\author{
Lujia Liu and T. David Harris*
}

\begin{abstract}
The incorporation of amino-substituted benzoquinoid bridging ligands into extended solids may provide a route to access light-weight metal-organic solids with high-temperature magnetic behavior and electronic conductivity. Reaction of $\mathrm{Zn}\left(\mathrm{NO}_{3}\right)_{2} \cdot 6 \mathrm{H}_{2} \mathrm{O}$ with 2,5-diamino3,6-dibromo-1,4-benzoquinone $\left({ }^{\mathrm{Br}} \mathrm{LH}_{2}\right)$ in $\mathrm{DMF}$ at $130{ }^{\circ} \mathrm{C}$ gave black block-shaped single crystals of the compound $\mathrm{Zn}\left({ }^{\mathrm{Br}} \mathrm{L}\right)(\mathrm{DMF})$, which features a structure comprised of onedimensional chains made up of alternating $\mathrm{Zn}^{\mathrm{II}}$ ions and ${ }^{\mathrm{Br}} \mathrm{L}^{2-}$ bridging ligands. The preservation of $\mathrm{NH}$ groups on ${ }^{\mathrm{Br}} \mathrm{L}^{2-}$ was confirmed by X-ray crystallography, a suite of spectroscopic measurements, and elemental analysis. To our knowledge, this chain compound represents the first structurally-characterized solid that contains amino-substituted benzoquinoid bridging ligands. Finally, an ambient temperature electronic conductivity value of $\sigma=1.076(5) \times 10^{-12}$ $\mathrm{S} \cdot \mathrm{cm}^{-1}$ was measured for the chain compound.
\end{abstract}

Keywords: chain compound; benzoquinone; diiminobenzoquinone; metal-organic 


\section{Introduction}

Derivatives of 2,5-dihydroxy-1,4-benzoquinone have been extensively employed as bridging ligands in the formation of coordination compounds, spanning dinuclear molecular complexes $^{1}$ to extended solids of dimensionalities from one to three. ${ }^{2}$ These ligands can direct the formation of metal compounds that display a wide range of interesting physical properties, owing largely to their ability to exist in both $S=0$ benzoquinoid and $S=1 / 2$ semiquinoid form. In particular, dinuclear complexes of benzo- and semiquinoid ligands have been shown to exhibit unusual electronic and magnetic phenomena, such as valence tautomerism, ${ }^{3}$ optical switching, ${ }^{4}$ electron delocalization, ${ }^{5}$ and strong metal-semiquinoid magnetic coupling. ${ }^{6}$

Despite the rich and diverse set of physical properties associated with the molecular benzoquinoid complexes noted above, the realization of analogous behavior in extended solids has been considerably more limited. Indeed, such solids may exhibit properties such as singlechain magnet behavior, ${ }^{7}$ bulk magnetic ordering, ${ }^{8}$ and electronic conductivity. ${ }^{9}$ The relative lack of progress stems largely from the fact that semiquinoid radical bridging ligands derived from dihydroxy-substituted benzoquinone have only recently been incorporated into extended solids. ${ }^{10}$ Nevertheless, these recent studies have shown that the resulting solids indeed demonstrate exceptional properties, including ferrimagnetic ordering up to $80 \mathrm{~K}^{10 \mathrm{a}}$ and electronic conductivity values up to $0.16(1) \mathrm{S} \cdot \mathrm{cm}^{-1} \cdot{ }^{10 \mathrm{~b}}$

One route to metal semiquinoid solids with magnetic behavior at higher temperature and larger values of electronic conductivity is through substitution of some or all oxygen donor atoms on the bridging ligand with nitrogen atoms (see Scheme 1), owing to the better energetic overlap between nitrogen and transition metals relative to oxygen. Indeed, both benzoquinoid ${ }^{11}$ and semiquinoid ${ }^{6 f, g}$ ligands that feature four nitrogen donors have been shown to exhibit much 
stronger metal-metal and metal-ligand radical coupling, respectively, than is observed in the oxygen-based analogues. Moreover, a copper solid derived from a hexaamino-substituted triphenylene ligand was shown to be 100 -fold more electronically conductive than the analogous hexahydroxy-based compound, ${ }^{12}$ with its nickel analogue exhibiting one of the highest conductivity values reported for any metal-organic solid. ${ }^{13}$

Despite this potential, to date no extended solid that incorporates an amino-substituted benzoquinoid bridging ligand has been structurally characterized. This is possibly due to a combination of two factors. First, replacing hydroxo with amino groups leads to an increase in $\mathrm{p} K_{\mathrm{a}}$, owing to the more electropositive nitrogen. The presence of these weakly acidic protons demands the use of strong bases during compound syntheses and gives rise to strong, irreversible bonding between metal ion and amido conjugate bases that can preclude the formation of crystalline products. In addition, 2,5-diamino-substituted benzoquinoids have been shown to readily hydrolyze in aqueous reactions with metal ions to instead give 2,5dihydroxybenzoquinoid metal compounds. ${ }^{10 \mathrm{~b}, 14}$ Herein, we report the synthesis and crystal structure of a zinc(II) 2,5-diamino-benzoquinonoid chain compound, which, to our knowledge, represents the first example of a structurally-characterized extended solid that contains aminosubstituted benzoquinoid bridging ligands.

\section{Synthesis and Characterization}

\subsection{General considerations}

The ligand 2,5-diamino-3,6-dibromo-1,4-benzoquinone $\left({ }^{\mathrm{Br}} \mathrm{LH}_{2}\right)$ was prepared following a literature procedure. ${ }^{15}$ The solvent $N, N$-dimethylformamide (DMF) was dried using a 
commercial solvent purification system from Pure Process Technology. All other reagents and solvents were obtained from commercial sources without further purification.

\subsection{Synthesis of $\mathrm{Zn}\left({ }^{\mathrm{Br}} \mathrm{L}\right)(\mathrm{DMF})(\mathbf{1})$}

Solid ${ }^{\mathrm{Br}} \mathrm{LH}_{2}$ (151 mg, $\left.0.510 \mathrm{mmol}\right)$ and $\mathrm{Zn}\left(\mathrm{NO}_{3}\right)_{2} \cdot 6 \mathrm{H}_{2} \mathrm{O}$ (294 mg, $\left.0.988 \mathrm{mmol}\right)$ were dissolved in anhydrous DMF (10 mL) in a $22.5 \mathrm{~mL}$ screw-cap borosilicate vial (Qorpak, GLC01006). The vial was capped and allowed to stand in an isothermal oven at $130{ }^{\circ} \mathrm{C}$ for $17 \mathrm{~h}$, during which a dark crystalline solid formed. The vial and its contents were then allowed to cool to ambient temperature, and the mother liquor was decanted. Fresh anhydrous DMF (3 mL) was added to the residual solid and then decanted. This washing process was repeated 10 times, until the supernatant appeared colorless to the eye. The residual solid was washed with diethyl ether five times ( $3 \mathrm{~mL}$ each), and then was collected by filtration. The residue was allowed to dry in air to afford 1 (136 mg, 61\%) as black block-shaped crystals suitable for single-crystal X-ray diffraction analysis. Anal. Calcd for $\mathrm{C}_{9} \mathrm{H}_{9} \mathrm{Br}_{2} \mathrm{~N}_{3} \mathrm{O}_{3} \mathrm{Zn}$ (1): C, 25.00; H, 2.10; N, 9.72\%. Found: C, 25.36; H, 2.26; N, 9.72\%.

\section{3. $X$-ray crystallography}

A single crystal of $\mathbf{1}$ was coated with Paratone oil and mounted on a MiTeGen MicroLoop. The crystallographic data were collected at $100 \mathrm{~K}$ on a Bruker APEX II diffractometer equipped with $\mathrm{Cu} \mathrm{K \alpha}$ microsource. Raw data were intergrated and corrected for Lorentz and polarization effects using Bruker Apex2 v. 2009.1. ${ }^{16}$ The space group was determined using XPREP based on systematic absence and E-statistics. ${ }^{17}$ The structure was solved using direct methods under SHELXT and refined with SHELXL using an Olex 2 
graphical interface. ${ }^{18}$ All zinc, bromine, oxygen, nitrogen, and carbon atoms were located in the electron density difference maps and refined anisotropically. Some restraints of distance and atomic displacement parameters were applied to the coordinated DMF molecule. Ideal positions for hydrogen atoms were calculated and refined as riding models. After the initial refinement, a significant residual electron density was found at $1.3 \AA$ away from bromine atom and normal to the ligand plane, indicating slight rotational disorder of the ligand through the $\mathrm{Zn}-\mathrm{Zn}$ axis. The disordered portion of the ligand was modeled using a SAME command, and the atomic displacement parameters were constrained to be the same as the main portion of the ligand. The occupancies of the two conformations were refined freely, but sum of occupancies was set to one. This treatment significantly improved the refinement statistics. A summary of crystallographic data is given in Table 1.

\subsection{Powder $X$-ray diffraction}

Powder X-ray diffraction data were collected for a polycrystalline sample of $\mathbf{1}$ in a boronrich capillary tube with $0.7 \mathrm{~mm}$ outer diameter. Data were collected on a Rigaku ATXG diffractometer equipped with $\mathrm{Cu} \mathrm{K} \alpha$ radiation, with a tube voltage and current of $50 \mathrm{kV}$ and 240 $\mathrm{mA}$, respectively.

\section{$2.5{ }^{13}$ C NMR spectroscopy}

The ${ }^{13} \mathrm{C}$ NMR spectra were collected at ambient temperature on a Bruker Avance III 500 $\mathrm{MHz}$ instrument equipped with a DCH CryoProbe. The spectrum of ${ }^{\mathrm{Br}} \mathrm{LH}_{2}$ was obtained from a solution in DMSO- $d_{6}$. Digestion of $\mathbf{1}$ was carried out by adding a solution of $\mathrm{DCl}$ in $\mathrm{D}_{2} \mathrm{O}(35 \%$ w/w, $10 \mu \mathrm{L})$ to a suspension of $\mathbf{1}(8.6 \mathrm{mg})$ in DMSO- $d_{6}(600 \mu \mathrm{L})$. Data were collected following 
complete dissolution of $\mathbf{1}$ (ca. $30 \mathrm{~min}$ ). The chemical shifts of both spectra were corrected using DMSO protons as the internal standard.

\subsection{Other physical measurements}

Infrared spectra were recorded on a Bruker Alpha FTIR spectrometer equipped with an attenuated total reflectance (ATR) accessory. X-ray photoelectron spectroscopy (XPS) data were carried out on a Thermo Scientific ESCALAB 580Xi instrument equipped with an electron flood gun and a scanning ion gun. Elemental analysis was performed by Midwest Microlab, LLC (Indianapolis, IN). Two-point dc conductivity data were collected at $295 \mathrm{~K}$ using a home-built pressed pellet system and a CH Instruments CHI660E electrochemical workstation.

\subsection{Computational details}

Computational porosity analysis was conducted using the RASPA code. ${ }^{19}$ The geometric surface area of the $\mathbf{1}$ was calculated using a method previously described. ${ }^{20}$ This method involves rolling a spherical probe, with a diameter set to the van der Waals diameter of $\mathrm{N}_{2}$ (3.72 $\AA),{ }^{21}$ over the atoms in one unit cell of $\mathbf{1}$. The diameters of the chain compound atoms were set to their van der Waals diameters, which were calculated by multiplying their Lennard-Jones well-depth diameters, $\sigma$, by $2^{1 / 6}$. The $\sigma$ values of all atoms were taken from the DREIDING force field. ${ }^{22}$ The pore fraction was calculated by the helium insertion method, which involves randomly inserting a helium atom into the lattice of $\mathbf{1}$ and then determining whether the helium atom overlaps with any of the atoms of the chain compound. ${ }^{23}$ This results in a fractional volume of the space that is accessible by a helium atom, with respect to its unit cell volume. Both geometric surface area and void fraction calculations gave values of 0 . 


\section{Results and Discussion}

Reaction of $\mathrm{Zn}\left(\mathrm{NO}_{3}\right)_{2} \cdot 6 \mathrm{H}_{2} \mathrm{O}$ with ${ }^{\mathrm{Br}} \mathrm{LH}_{2}$ (see Scheme 2) in DMF at $130{ }^{\circ} \mathrm{C}$ for $17 \mathrm{~h}$ resulted in black block-shaped crystals of $\mathrm{Zn}\left({ }^{\mathrm{Br}} \mathrm{L}\right)(\mathrm{DMF})(\mathbf{1})$ in 61\% yield. Single-crystal X-ray diffraction analysis revealed that $\mathbf{1}$ crystallizes in the centrosymmetric orthorhombic space group Pnma. Overall, the structure is comprised of zigzag one-dimensional chains that propagate along the crystallographic $b$ axis (see Figure 1, upper). Each chain is made up of alternating $\mathrm{Zn}^{\mathrm{II}}$ ions and ${ }^{\mathrm{Br}} \mathrm{L}^{2-}$ bridging ligands and features a nearest neighbor $\mathrm{Zn} \cdots \mathrm{Zn}$ distance of 7.927(1) $\AA$ and a next nearest neighbor $\mathrm{Zn} \cdots \mathrm{Zn}$ distance of $14.7981(6) \AA$, with the latter value corresponding to the length of the unit cell edge along the $b$ direction. Along the $c$ axis, chains are closely nested with one another to form a two-dimensional sheet that lies in the $b c$ plane, with closest interchain $\mathrm{Zn} \cdots \mathrm{Zn}$ and $\mathrm{Zn} \cdots \mathrm{C}_{\mathrm{DMF}}$ distances of $8.833(4)$ and 4.07(4) $\AA$, respectively (see Figure 1, lower left), with the former value corresponding to the length of the unit cell edge along the $c$ direction. Along the $a$ axis, alternating sheets make up an ABAB pattern, where adjacent intersheet chains are crystallographically related through an inversion center defined by the centroid of each pair of intra-chain pair of neighboring $\mathrm{Zn}^{\mathrm{II}}$ ions (see Figure 1, lower right). The closest corresponding inter-chain $\mathrm{Zn} \cdots \mathrm{Zn}$ distance is 5.077(3) $\AA$.

The solid-state structure of $\mathbf{1}$ results in tight packing of chains to give an overall nonporous three-dimensional structure with a crystal density of $2.277 \mathrm{~g} / \mathrm{cm}^{3}$. This dense packing is further illustrated through computational porosity analysis using the RASPA software package. ${ }^{19}$ Here, a geometric surface area calculation indicates that $\mathbf{1}$ exhibits no internal surface area accessible by a nitrogen probe, in additional to no internal void space accessible by a helium probe. $^{20,23}$ Finally, note that the phase purity of the bulk product was confirmed by elemental 
analysis and power X-ray diffraction, with the latter technique giving a pattern that matches closely with the pattern simulated from single-crystal X-ray diffraction analysis (see Figure 3a).

As shown in Figures 1 and 2, each $\mathrm{Zn}^{\mathrm{II}}$ center resides in a distorted square pyramidal coordination environment, with an $\left[\mathrm{N}_{2} \mathrm{O}_{2}\right]$ basal plane comprised of two syn-oriented bound ${ }^{\mathrm{Br}} \mathrm{L}^{2-}$ ligands and the oxygen atom from a DMF molecule occupying the apical position. In order to minimize ligand-ligand electrostatic repulsion, the $\mathrm{Zn}^{\mathrm{II}}$ center is displaced out of the $\left[\mathrm{N}_{2} \mathrm{O}_{2}\right]$ plane by $0.54 \AA$. This displacement, in conjunction with an alternating direction of apical projection of the square pyramids, gives rise to the overall zig-zag chain topology that is described above.

The mean Zn-O and Zn-N bond distances of 2.072(9) and 2.05(2) $\AA$, respectively, are consistent with the presence of $\mathrm{d}^{10} \mathrm{Zn}^{\mathrm{II}}$ ions. ${ }^{24}$ Within ${ }^{\mathrm{Br}} \mathrm{L}^{2-}$, the $\mathrm{C} 1-\mathrm{O} 1$ and $\mathrm{C} 3-\mathrm{N} 1$ bond distances of 1.29(1) and 1.29(2) $\AA$, respectively, fall intermediate between single and double bonds. ${ }^{25}$ Concordant with these intermediate distances, the C1-C2 and C2-C3 bond distances fall within the range of aromatic C-C bonds. Taken together, these collective bond distances suggest delocalized bonding within the O1-C1-C2-C3-N1 system. In line with this assignment, the C3C1' distance of 1.58(2) $\AA$ is clearly diagnostic of a C-C single bond. Note, however, that the C-C distance observed here is slightly too long for a C-C single bond (e.g. $1.54 \AA$ in alkanes), and this anomalous value likely stems from relatively large atomic displacement values in the structure of 1 and/or a slight rotational disorder of the ligand along the $\mathrm{Zn} \cdots \mathrm{Zn}$ axis.

The electronic structure suggested for ${ }^{\mathrm{Br}} \mathrm{L}^{2-}$ by the crystal structure of $\mathbf{1}$ is consistent with homo-substituted $\mathrm{O}_{4}$ - and $\mathrm{N}_{4}$-based benzoquinoid ligands that have been characterized in dinuclear molecular compounds, ${ }^{1 e, 26}$ rather than the bis(phenolate)diimine structure typically observed in complexes of $\mathrm{N}_{2} \mathrm{O}_{2}$-substituted benzoquinoids. ${ }^{25,}{ }^{27}$ However, while the crystal 
structure is best modeled with distinct $\mathrm{O}$ and $\mathrm{N}$ atoms in ${ }^{\mathrm{Br}} \mathrm{L}^{2-}$, this unexpected structure, in conjunction with the presence of identical $\mathrm{C}-\mathrm{O}$ and $\mathrm{C}-\mathrm{N}$ distances, suggests that the relative orientations of ${ }^{\mathrm{Br}} \mathrm{L}^{2-}$ across different chains in $\mathbf{1}$ are crystallographically disordered. As such, the true electronic structure of ${ }^{\mathrm{Br}} \mathrm{L}^{2-}$ may in fact correspond to the bis(phenolate)diimine configuration that is expected based on literature precedent.

Previous reports have shown that reaction of ${ }^{\mathrm{H}} \mathrm{LH}_{2}$ (see Scheme 2) with divalent transition metal ions under hydrothermal conditions leads to ligand hydrolysis to give dianionic three-dimensional solids that contain exclusively 2,5 -dihydroxybenzoquinoid ligands. ${ }^{14,10 \mathrm{~b}}$ In contrast, similar ligand hydrolysis does not occur in the formation of $\mathbf{1}$. As crystallographic differentiation of oxygen and nitrogen atoms can be difficult due to the similar scattering factors of the two elements, the preservation of ${ }^{\mathrm{Br}} \mathrm{L}^{2-}$ ligands in $\mathbf{1}$ was confirmed through elemental analysis and a suite of spectroscopic techniques. First, the ${ }^{13} \mathrm{C}$ NMR spectrum of $\mathbf{1}$ in DMSO- $d_{6}$, following digestion by $\mathrm{DCl}$ and $\mathrm{D}_{2} \mathrm{O}$, displays three resonances at 170, 151, and $90 \mathrm{ppm}$ that are identical to those observed for a DMSO- $d_{6}$ solution of ${ }^{\mathrm{Br}} \mathrm{LH}_{2}$ (see Figure 3b). The remaining three resonances observed for $\mathbf{1}$ at 163,36 , and $31 \mathrm{ppm}$ are attributed to DMF. ${ }^{28}$ In addition to demonstrating the presence of ${ }^{\mathrm{Br}} \mathrm{L}^{2-}$ in $\mathbf{1}$, this experiment provides evidence that no significant number of 1,4-dihydroxybenzoquinoid ligands are present. Indeed, in the case of hydrolysis, we would expect to observe two new carbon resonances at or near 163 and 103 ppm that correspond to the resulting 2,5-dihydroxybenzoquinoid. ${ }^{29}$ Moreover, the solid-state FT-IR spectrum of $\mathbf{1}$ features a sharp peak at $3292 \mathrm{~cm}^{-1}$, which can be attributed to the $\mathrm{N}-\mathrm{H}$ bond in ${ }^{\mathrm{Br}} \mathrm{L}^{2-}$ (see Figure 3c). Finally, XPS analysis revealed the presence of two distinct nitrogen 1s electron binding energies, which correspond to the two disparate bonding environments at nitrogen within ${ }^{\mathrm{Br}} \mathrm{L}^{2-}$ and DMF ligands (see Figure 3d). 
As an initial test of possible electronic conductivity in solids based on ${ }^{\mathrm{Br}} \mathrm{L}^{2-}$, the conductivity for a pressed pellet of $\mathbf{1}$ was measured at $295 \mathrm{~K}$. This measurement revealed a conductivity value of $\sigma=1.076(5) \times 10^{-12} \mathrm{~S} \cdot \mathrm{cm}^{-1}$ (see Figure 4), which falls in the range of $\sigma<$ $10^{-8} \mathrm{~S} \cdot \mathrm{cm}^{-1}$ typically associated with insulators. ${ }^{30}$ This small value likely results from a combination of low structural dimensionality, completely filled $3 \mathrm{~d}$ orbitals of $\mathrm{Zn}{ }^{\mathrm{II}}$ ions, and the diamagnetic composition of the ${ }^{\mathrm{Br}} \mathrm{L}^{2-}$. Nevertheless, the presence of a measurable conductivity in $\mathbf{1}$ perhaps suggests that analogous structures containing redox-active, non- $\mathrm{d}^{10}$ metal ions and/or paramagnetic isomers of ${ }^{\mathrm{x}} \mathrm{L}^{n-}$ could exhibit much higher values. Finally, no changes were observed in the PXRD pattern or IR spectrum for the pressed pellet following the conductivity measurement, indicating that no structural phase change or redox chemistry occurred during application of the voltage.

\section{Conclusions and Outlook}

The foregoing results demonstrate that 2,5-diaminobenquinoid bridging ligands can give rise to monocrystalline extended solids. Specifically, reaction of $\mathrm{Zn}\left(\mathrm{NO}_{3}\right)_{2} \cdot 6 \mathrm{H}_{2} \mathrm{O}$ with ${ }^{\mathrm{Br}} \mathrm{LH}_{2}$ in DMF at $130{ }^{\circ} \mathrm{C}$ gave the compound $\mathrm{Zn}\left({ }^{\mathrm{Br}} \mathrm{L}\right)(\mathrm{DMF})$, whose structure is comprised of onedimensional chains made up of alternating $\mathrm{Zn}^{\mathrm{II}}$ ions and ${ }^{\mathrm{Br}} \mathrm{L}^{2-}$ bridging ligands. The preservation of $\mathrm{NH}$ groups on ${ }^{\mathrm{Br}} \mathrm{L}^{2-}$ was confirmed by X-ray crystallography, a suite of spectroscopic measurements, and elemental analysis. Additionally, an ambient temperature electronic conductivity value of $\sigma=1.076(5) \times 10^{-12} \mathrm{~S} \cdot \mathrm{cm}^{-1}$ was measured for the chain compound and highlights the possibility of larger values in analogous compounds. Our current efforts are aimed toward incorporation of redox-active metal ions into related structures, with the goal of realizing one-dimensional conductive metal-organic magnets. 


\section{Appendix A. Supporting Information Available}

CCDC 1495939 contains the supplementary crystallographic data for this paper. These data can be obtained free of charge via www.ccdc.cam.ac.uk/data_request/cif, or by emailing data_request@ccdc.cam.ac.uk, or by contacting The Cambridge Crystallographic Data Centre, 12, Union Road, Cambridge CB2 1EZ, UK; fax: +44 1223336033.

\section{Acknowledgments}

This research was funded by the National Science Foundation through Grant DMR1351959 and by Northwestern University (NU). We thank A. Banisafar for experimental assistance. The Keck-II Facility of the NUANCE Center and the J. B. Cohen X-ray Diffraction Facility at NU have received support from the NU-MRSEC (NSF DMR-1121262) and IIN. 

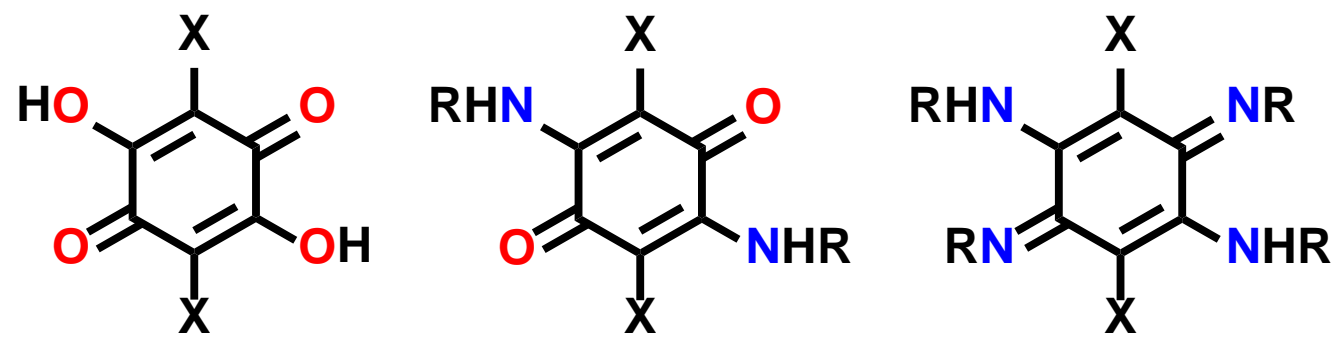

Scheme 1. Benzoquinoid bridging ligands with oxygen and/or nitrogen donor atoms.
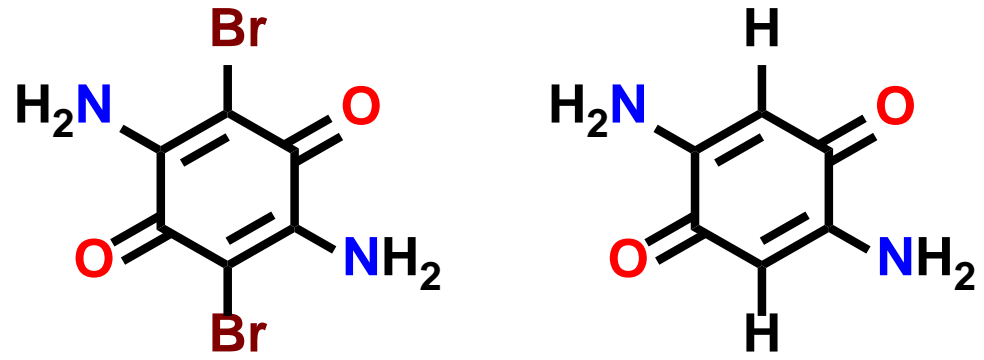

Scheme 2. Molecular structures of ${ }^{\mathrm{Br}} \mathrm{LH}_{2}$ (left) and ${ }^{\mathrm{H}} \mathrm{LH}_{2}$ (right). 
Table 1 | Crystallographic data for $\mathbf{1}$.

\begin{tabular}{|c|c|}
\hline & 1 \\
\hline Empirical formula & $\mathrm{C}_{9} \mathrm{H}_{9} \mathrm{Br}_{2} \mathrm{~N}_{3} \mathrm{O}_{3} \mathrm{Zn}$ \\
\hline Formula weight, g/mol & 432.38 \\
\hline Crystal system & orthorhombic \\
\hline Space group & Pnma \\
\hline Wavelength, $\AA$ & 1.54178 \\
\hline Temperature, K & 100 \\
\hline$a, \AA$ & $9.6500(5)$ \\
\hline$b, \AA$ & $14.7981(6)$ \\
\hline$c, \AA$ & 8.8332(7) \\
\hline$\alpha,^{\circ}$ & 90 \\
\hline$\beta,^{\circ}$ & 90 \\
\hline$\gamma,{ }^{o}$ & 90 \\
\hline$V, \AA^{3}$ & $1261.4(1)$ \\
\hline Z & 4 \\
\hline$\rho_{\text {calcd }}, \mathrm{mg} / \mathrm{m}^{3}$ & 2.277 \\
\hline$\mu, \mathrm{mm}^{-1}$ & 10.191 \\
\hline Refections coll./unique & $7122 / 1167$ \\
\hline$R_{\text {int }}$ & 0.0505 \\
\hline${ }^{a} R_{1}(I>2 \sigma(I))$ & 0.0995 \\
\hline${ }^{b} w R_{2}$ (all) & 0.2333 \\
\hline GoF & 1.149 \\
\hline${ }^{a} R_{1}=\Sigma|| F_{0}|-| F_{C}|| / \Sigma\left|F_{0}\right|$ & \\
\hline
\end{tabular}



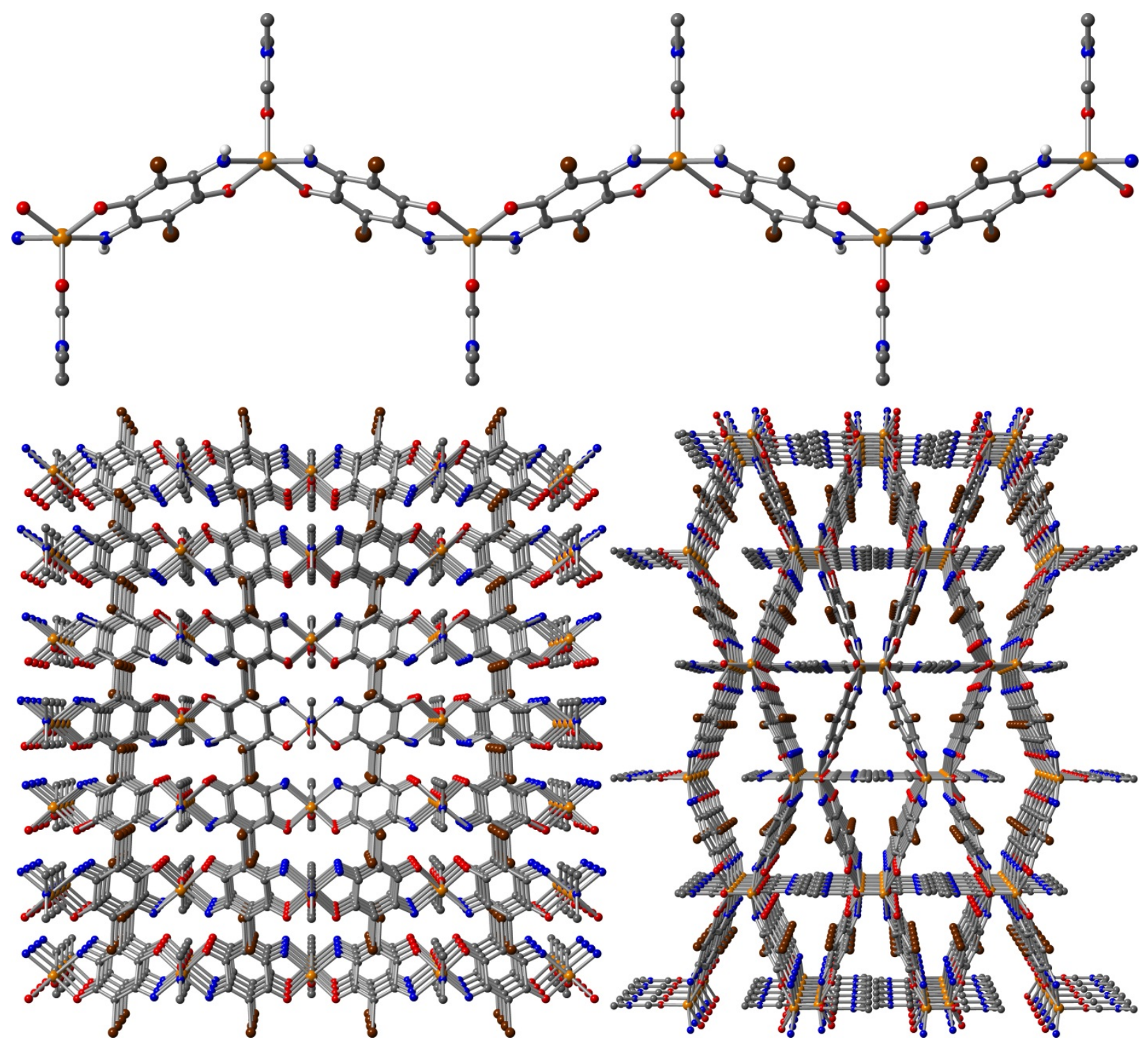

Figure 1. Crystal structure of 1, where orange, brown, red, blue, gray, and white spheres represent $\mathrm{Zn}, \mathrm{Br}, \mathrm{O}, \mathrm{N}, \mathrm{C}$ and $\mathrm{H}$ atoms, respectively; selected $\mathrm{H}$ atoms are omitted for clarity. Views depict segment of single chain (upper) and packing diagrams, as viewed along the crystallographic $c$ (lower left) and $a$ (lower right) axes. 


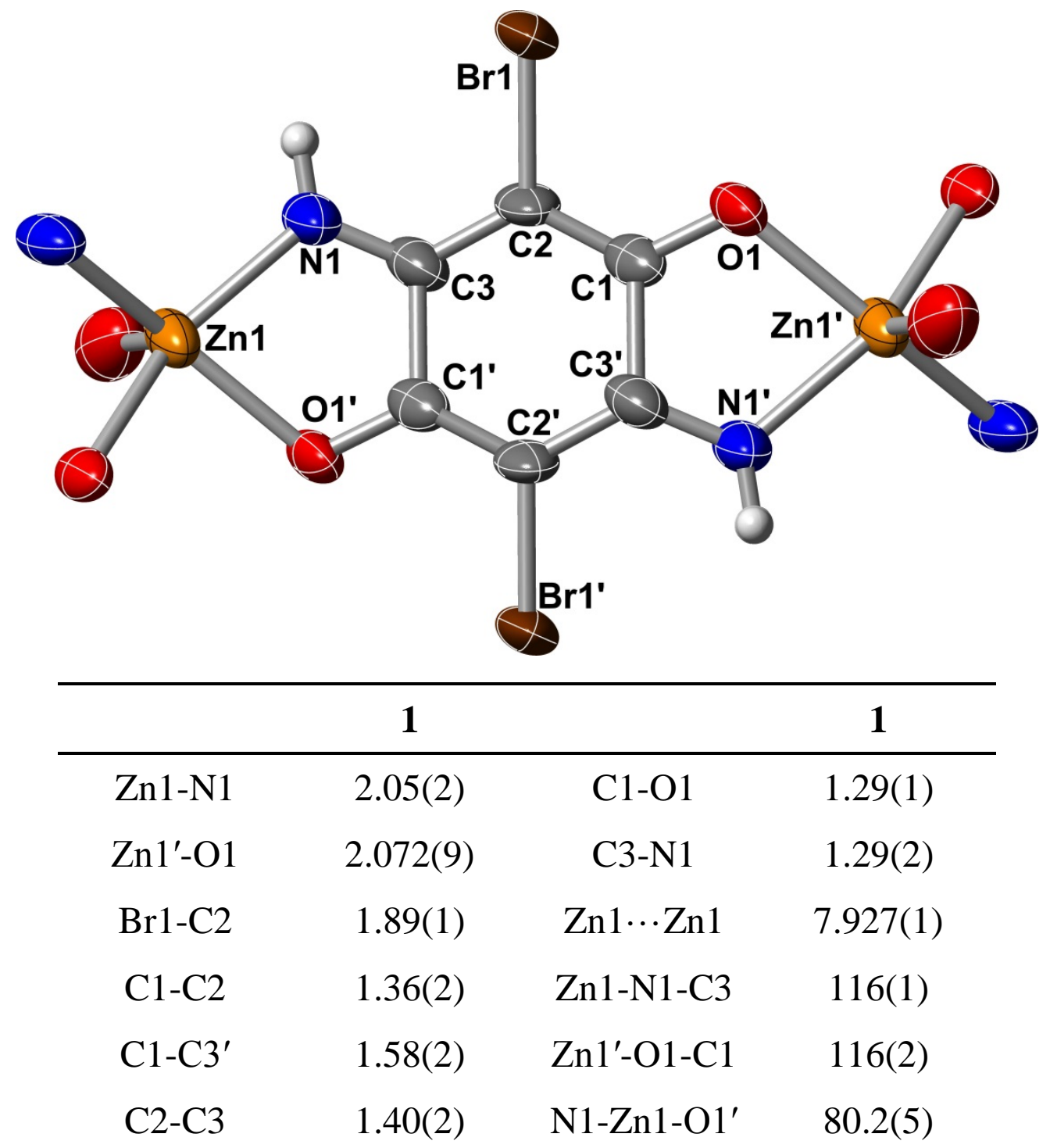

Figure 2. Upper: Crystal structure and atomic labeling scheme of 1, with non-H atoms shown as ellipsoids at the 50\% probability level. Orange, brown, red, blue, and gray ellipsoids represent Fe, $\mathrm{Br}, \mathrm{O}, \mathrm{N}$, and $\mathrm{C}$ atoms, respectively; $\mathrm{H}$ atoms are shown as white spheres of arbitrary radius. Non-O atoms of the DMF ligands are omitted for clarity. Lower: Table of selected interatomic distances $(\AA)$ and angles $\left(^{\circ}\right)$. 
A

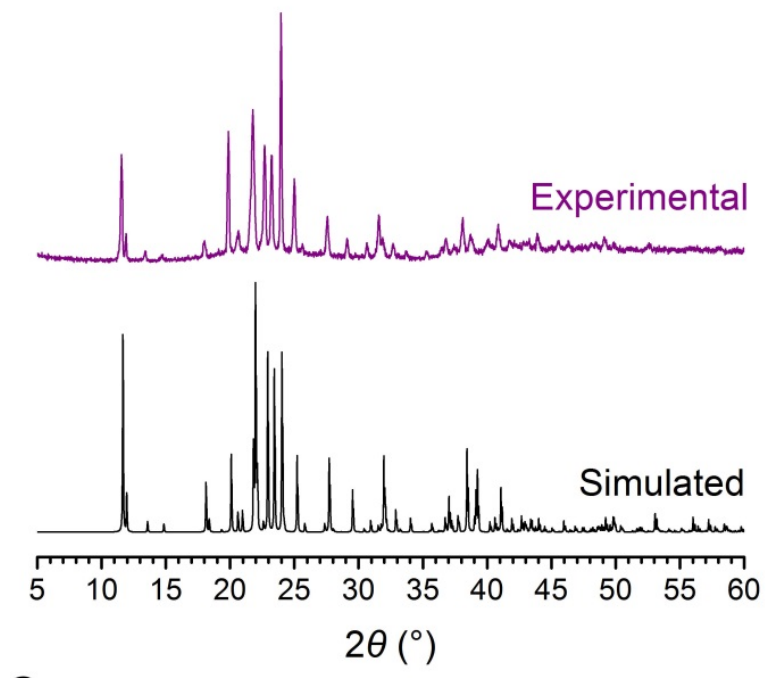

C

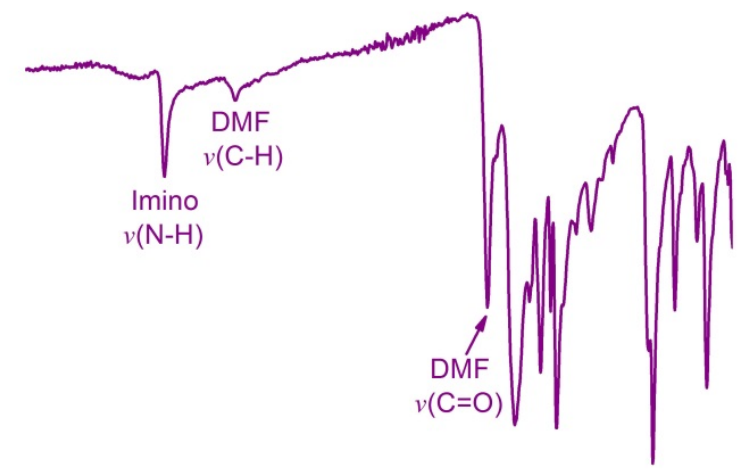

40003600320028002400200016001200800400 Wavenumbers $\left(\mathrm{cm}^{-1}\right)$
B

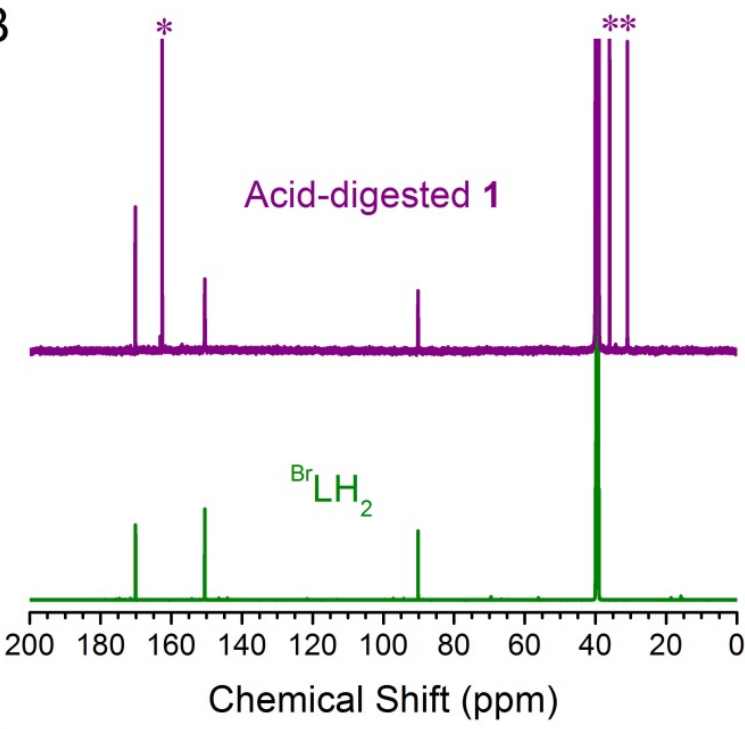

D

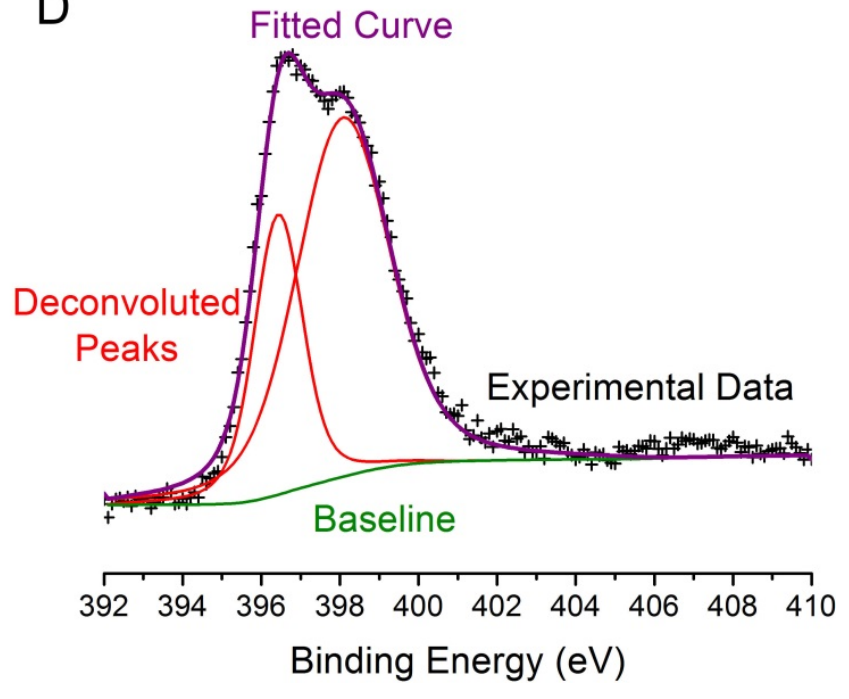

Figure 3. (A) Experimental and simulated PXRD patterns for 1. (B) ${ }^{13} \mathrm{C}$ NMR spectra for aciddigested 1 and ${ }^{\mathrm{Br}} \mathrm{LH}_{2}$; peaks denoted with asterisks are assigned to DMF molecules. (C) Solidstate FT-IR spectrum for $\mathbf{1}$. (D) XPS data for 1, highlighting the presence of two distinct 1s binding energies of $\mathrm{N}$. 


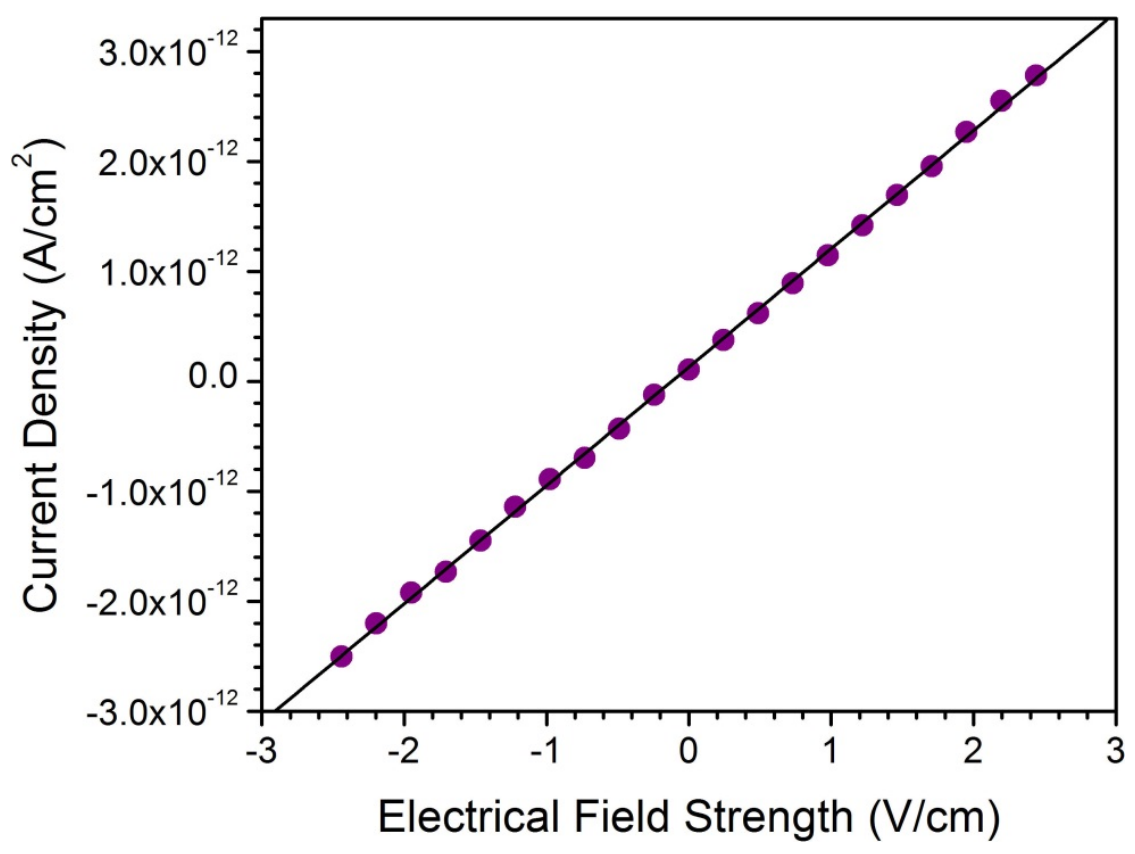

Figure 4. I-V curve for $\mathbf{1}$, collected at $295 \mathrm{~K}$, with a fit to the data shown as a black line. 


\section{References}

(1) Selected references: (a) Pierpont, C. G.; Francesconi, L. C.; Hendrickson, D. N. Inorg. Chem. 1977, 16, 2367. (b) Tinti, F.; Verdaguer, M.; Kahn, O.; Savariault, J-M. Inorg.Chem. 1987, 26, 2380. (c) Folgado, J. V.; Ibáñez, R.; Coronado, E.; Beltrn, Beltrán, D.; Savariault, J. M.; Galy, J. Inorg. Chem. 1988, 27, 19. (d) Chatterjee, P. B.; Bhattacharya, K.; Kundu, N.; Choi, K-Y.; Clérac, R.; Chaudhury, M. Inorg. Chem. 2009, 48, 804. (e) Miller, J. S.; Min, K. S. Angew. Chem. Int. Ed. 2009, 48, 262. (f) Schweinfurth, D.; Klein, J.; Hohloch, S. Dechert, S.; Demeshko, S.; Meyer, F. Sarkar, B. Dalton Trans. 2013, 42, 6944.

(2) Selected references: (a) Weiss, A.; Riegler, E.; Robl, C. Z. Naturforsh 1986, 41b, 1501. (b) Kawata, S.; Kitagawa, S.; Kondo, M.; Furuchi, I.; Munakata, M. Angew. Chem. Int. Ed. 1994, 33, 1759. (c) Abrahams, B. F.; Coleiro, J.; Hoskins, B. F.; Robson, R. Chem. Commun. 1996, 603. (d) Kitagawa, S.; Kawata, S. Coord. Chem. Rev. 2002, 224, 11. (e) Nagayoshi, K.; Kabir, M. K.; Tobita, H.; Honda, K.; Kawahara, M.; Katada, M.; Adachi, K.; Nishikawa, H.; Ikemoto, I.; Kumagai, H.; Hosokoshi, Y.; Inoue, K.; Kitagawa, S.; Kawata, S. J. Am. Chem. Soc. 2003, 125, 221. (f) Luo, T.-T.; Liu, Y.-H.; Tsai, H.-L.; Su, C.-C.; Ueng, C.-H.; Lu, K.-L. Eur. J. Inorg. Chem. 2004, 4253. (g) Nakabayashi, K.; Ohkoshi, S.-i. Inorg. Chem. 2009, 48, 8647. (h) Atzori, M.; Benmansour, S.; Espallargas, G. M.; Clemente-León, M.; Abhervé, A.; Gómez-Claramunt, P.; Coronado, E.; Artizzu, F.; Sessini, E.; Deplano, P.; Serpe, A.; Mercuri, M. L.; Gomez García, C. J. Inorg. Chem. 2013, 52, 10031.

(3) (a) Carbonera, C.; Dei, A.; Létard, J-F.; Sangregorio, C.; Sorace, L. Angew. Chem. Int. Ed. 2004, 43, 3136. (b) Tao, J.; Maruyama, H.; Sato, O. J. Am. Chem. Soc. 2006, 128, 1790. (c) Li, B.; Tao, J.; Sun, H-L.; Sato, O.; Huang, R-B.; Zheng, L.-S. Chem. Commun. 2008, 2269. (d) Min, K. S.; DiPasquale, A. G.; Rheingold, A. L. White, H. S.; Miller, J. S. J. Am. Chem. Soc. 2009, 131, 6229.

(4) (a) Schwab, P. F. H.; Diegoli, S.; Biancardo, M.; Bignozzi, C. A. Inorg. Chem. 2003, 42, 6613. (b) Deibel, N.; Sommer, M.; Hohloch, S.; Schwann, J.; Schweinfurth, D.; Ehret, F.; Sarkar, B. Organometallics 2014, 33, 4756.

(5) (a) Heinze, K.; Huttner, G.; Walter, O. Eur. J. Inorg. Chem. 1999, 1999, 593. (b) Gupta, P.; Das, A.; Basuli, F.; Castineiras, A.; Sheldrick, W. S.; Mayer-Figge, H.; Bhattacharya, S. Inorg. Chem. 2005, 44, 2081. (c) Gaudette, A. I.; Jeon, I.-R.; Anderson, J. S.; Grandjean, F.; Long, G. J.; Harris, T. D. J. Am. Chem. Soc. 2015, 137, 12617.

(6) Dei, A.; Gatteschi, D.; Pardi, L.; Russo, U. Inorg. Chem. 1991, 30, 2589. (b) Min, K. S.; Rheingold, A. L.; DiPasquale, A. G.; Miller, J. S. Inorg. Chem. 2006, 45, 6135. (c) Min, K. S.; DiPasquale, A. G.; Golen, J. A.; Rheingold, A. L.; Miller, J. S. J. Am. Chem. Soc. 2007, 129, 2360. (d) Guo, D.; McCusker, J. K. Inorg. Chem. 2007, 46, 3257. (e) Baum, A. E.; Lindeman, S. V.; Fiedler, A. T. Chem. Commun. 2013, 49, 6531. (f) Jeon, I.-R.; Park, J. G.; Xiao, D. J.; Harris, T. D. J. Am. Chem. Soc. 2013, 135, 16845. (g) DeGayner, J. A.; Jeon, I.-R.; Harris, T. D. Chem. Sci. 2015, 6, 6639.

(7) (a) Coulon, C.; Miyasaka, H.; Clérac, R. Struct. Bonding (Berlin) 2006, 122, 163. (b) Miyasaka, H.; Julve, M.; Yamashita, M.; Clérac, R. Inorg. Chem. 2009, 48, 3420. 
(8) (a) Kurmoo, M. Chem. Soc. Rev. 2009, 38, 1353. (b) Dechambenoit, P.; Long, J. R. Chem. Soc. Rev. 2011, 40, 3249.

(9) Sun, L.; Campbell, M. G.; Dincă, M. Angew. Chem. Int. Ed. 2016, 55, 3566.

(10) (a) Jeon, I.-R.; Negru, B.; Van Duyne, R. P.; Harris, T. D. J. Am. Chem. Soc. 2015, 137, 15699. (b) Darago, L. E.; Aubrey, M. L.; Yu, C. J.; Gonzalez, M. I.; Long, J. R. J. Am. Chem. Soc. 2015, 137, 15703. (c) Halis, S.; Inge, A. K.; Dehning, N.; Weyrich, T.; Reinsch, H. Stock, N. Inorg. Chem. 2016, 10.1021/acs.inorgchem.6b00661.

(11) Schweinfurth, D.; Khusniyarov, M. M.; Bubrin, D.; Hohloch, S.; Su, C.-Y.; Sarkar, B. Inorg. Chem. 2013, 52, 10332.

(12) Campbell, M. G.; Liu, S. F.; Swager, T. M.; Dincă, M. J. Am. Chem. Soc. 2015, 137, 13780.

(13) Sheberla, D.; Sun, L.; Blood-Forsythe, M. A.; Er, S.; Wade, C. R.; Brozek, C. K.; Aspuru-Guzik, A.; Dincă, M. J. Am. Chem. Soc. 2014, 136, 8859.

(14) Abrahams, B. F.; Hudson, T. A.; McCormick, L. J.; Robson, R. Cryst. Growth Des. 2011, 11, 2717.

(15) Mereyala, H. B.; Chary, M. V.; Kantevari, S. Synthesis 2007, 2007, 187.

(16) APEX2, v. 2009; Bruker Analytical X-ray Systems, Inc: Madison, WI, 2009.

(17) XPREP, v. 6.10; Bruker Analytical X-ray Systems, Inc: Madison, WI, 2000.

(18) (a) Sheldrick, G. M. Acta Cryst. 2008, A64, 112. (b) Dolomanov, O. V.; Bourhis, L. J.; Gildea, R. J.; Howard, J. A. K.; Puschmann, H. J. Appl. Crystallogr. 2009, 42, 339.

(19) Dubbeldam, D.; Calero, S.; Ellis, D. E.; Snurr, R. Q. Mol. Simul. 2016, 42, 81.

(20) Düren, T.; Millange, F.; Férey, G.; Walton, K. S.; Snurr, R. Q. J. Phys. Chem. C 2007, 111, 15350.

(21) Bae, Y.-S.; Yazaydin, A. Ö.; Snurr, R. Q. Langmuir 2010, 26, 5475.

(22) Mayo, S. L.; Olafson, B. D.; Goddard, W. A. J. Phys. Chem. 1990, 94, 8897.

(23) Frost, H.; Düren, T.; Snurr, R. Q. J. Phys. Chem. B 2006, 110, 9565.

(24) (a) Najafi, E.; Amini, M. M.; Ng, S. W. Acta Cryst. E 2011, 67, m1283. (b) Vranec, P.; Potocnak, I. Inorg. Chem. Commun. 2013, 35, 200.

(25) Park, J. G.; Jeon, I.-R.; Harris, T. D. Inorg. Chem. 2015, 54, 359.

(26) Sarkar, Schweinfurth, Deibel, Weisser Coord. Chem. Rev. 2015, 293, 250.

(27) (a) Jia, W.-G.; Han, Y.-F.; Lin, Y-J.; Weng, L.-H.; Jin, G-X. Organometallics 2009, 28, 3459. (b) Zhang, D.; Jin, G.-X. Organometallics, 2003, 22, 2851. (c) Das, H. S.; Weisser, F.; Schweinfurth, D.; Su, C-Y.; Bogani, L.; Fiedler, J.; Sarkar, B. Chem. Eur. J. 2010, 16, 2977. (d) Sommer, M. G.; Schweinfurth, D.; Weisser, F.; Hohloch, S.; Sarkar, B. Organometallics 2013, 32, 2069. (e) Schweinfurth, D.; Khusniyarov, M. M.; Bubrin, D.; Hohloch, S.; Su, C.-Y.; Sarkar, B. Inorg. Chem. 2013, 52, 10332. (f) Schweinfurth, D.; Rechkemmer, Y.; Hohloch, S.; Deibel, N.; Peremykin, I.; Fiedler, J.; Marx, R.; Neugebauer, P.; van Slageren, J.; Sarkar, B. Chem. Eur. J. 2014, 20, 3475. 
(28) (a) Gottlieb, H. E.; Kotlyar, V.; Nudelman, A. J. Org. Chem. 1997, 62, 7512. (b) Flumer, G. R.; Miller, A. J. M.; Sherden, N. H.; Gottlieb, H. E.; Nudelman, A.; Stoltz, B. M.; Bercaw, J. E.; Goldberg, K. I. Organometallics 2010, 29, 2176.

(29) Takeshita, H.; Mori, A.; Kusaba, T.; Watanabe, H. Bull. Chem. Soc. Jpn. 1987, 60, 4325.

(30) Jeon, I.-R.; Sun, L.; Negru, B.; Van Duyne, R. P.; Dincă, M.; Harris, T. D. J. Am. Chem. Soc. 2016, 138, 6583. 


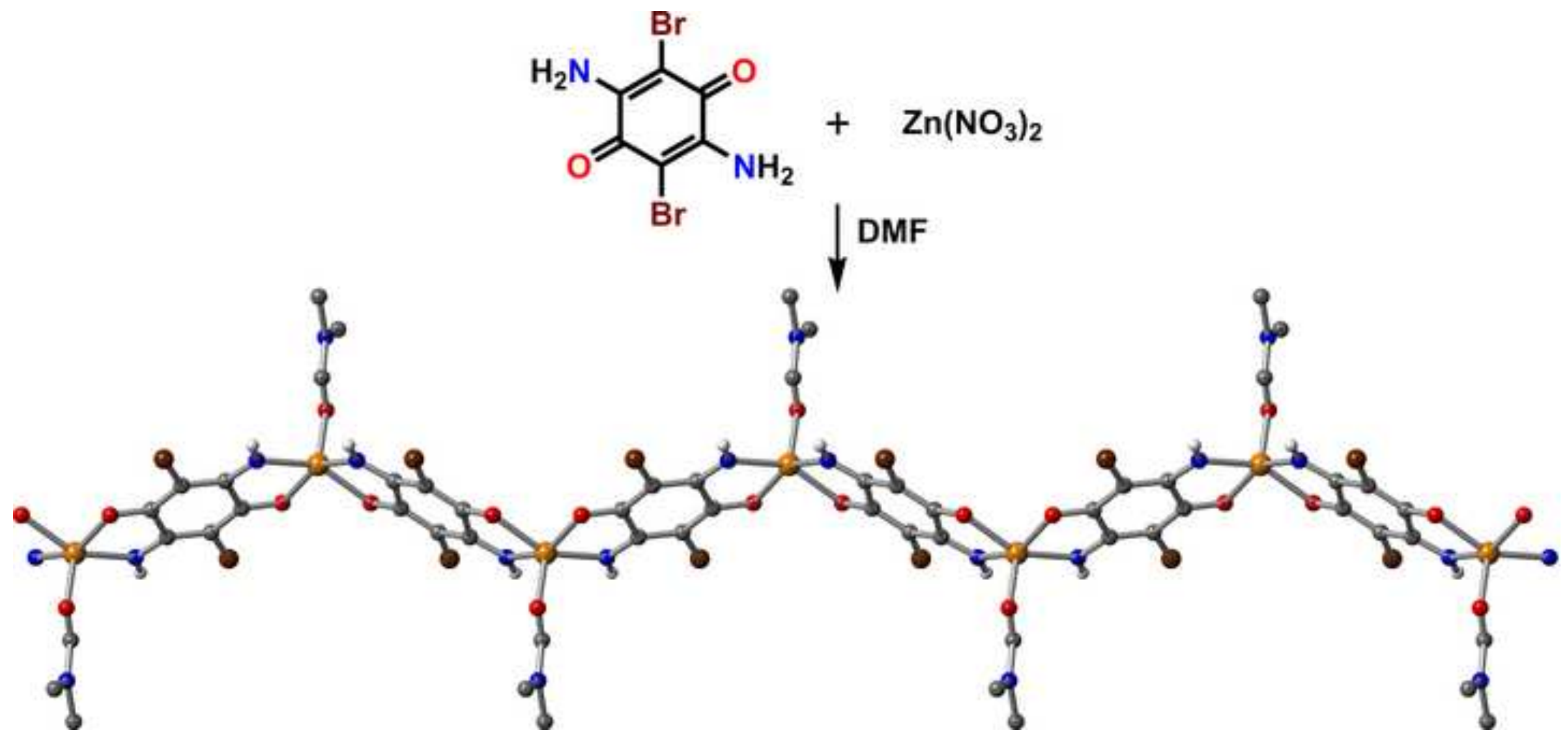

This paper reports the synthesis and characterization of a zinc 2,5-diiminobenzoquinoid chain compound, the first example of a structurally-characterized extended solid that contains amino-substituted benzoquinoid bridging ligands. 